\title{
Um olhar exploratório sobre os resíduos de serviços de saúde para os cursos da área da saúde numa universidade comunitária do Sul do Brasil
}

A view on the exploration of waste services for health courses of health in a university community in South Brazil

Adriani Maria Muller', Djalma Dias da Silveira² , Elpidio Oscar Benitez Nara ${ }^{3}$, Liane Mahlmann Kipper ${ }^{4}$, Jorge André Ribas Moraes ${ }^{5}$

\author{
'Mestre, Docente de Ciências Administrativas e Assistente Administrativo - Santa Cruz do Sul, RS - Brasil \\ ${ }^{2}$ Doutor, Professor associado da Universidade Federal de Santa Maria - Santa Maria, RS - Brasil \\ ${ }^{3}$ Doutor, Professor adjunto da Universidade de Santa Cruz do Sul - Santa Cruz do Sul, RS - Brasil \\ ${ }^{4}$ Doutor, professora titular e coordenadora do mestrado em Sistemas e Processos Industriais - Santa Cruz do Sul, RS - Brasil \\ ${ }^{5}$ Doutor, professor tempo parcial da Universidade de Santa Cruz do Sul - Santa Cruz do Sul, RS - Brasil
}

\section{Resumo}

Esta pesquisa objetiva realizar uma investigação sobre os resíduos de serviços de saúde para os cursos da área da saúde numa universidade comunitária do sul do Brasil com base nas orientações fornecidas pela legislação brasileira vinculada ao setor de saúde e no Sistema de Gestão Ambiental, estabelecido pela NBR ISO 14001, para a proposição de um modelo para Gerenciamento de Resíduos de Serviços de Saúde. Para isto, foram aplicados dois questionários: um para coleta de dados dos alunos e outro para docentes e funcionários. A pesquisa classificou-se como exploratória descritiva e usou abordagens de integração entre análise qualitativa e quantitativa. Foi constatado que $94 \%$ dos alunos desconhecem a legislação referente aos Resíduos de Serviços de Saúde - RSS e que $82 \%$ dos docentes e funcionários não conhecem a destinação desses resíduos. Outros resultados da pesquisa demonstraram a necessidade de informações mais amplas e consistentes em relação aos RSS gerados nas aulas práticas e no atendimento à comunidade. O conhecimento das técnicas aplicadas tanto pelos alunos quanto pelos docentes e funcionários, focadas especificamente nas áreas de atuação, deixam a desejar no que diz respeito à legislação e ao gerenciamento dos RSS. Percebeu-se que esse assunto não é tratado pelos docentes, discentes e técnicos administrativos como relevante, embora, todos saibam da sua importância vital à saúde de cada sujeito envolvido. Após os resultados obtidos, foram elaboradas sugestões sistemáticas sobre a gestão de Resíduos de Serviços de Saúde gerados em atividades de ensino que se constitui num conjunto de ações visando à qualidade e à eficiência das práticas acadêmicas, enfatizando a educação ambiental.

Palavras-chave: Educação Ambiental, Política Ambiental Interna, Gerenciamento de Resíduos de Serviço de Saúde.

\begin{abstract}
This research aims a management system Waste Health Services - RSS - courses for health care from a community college, based on guidance provided by the Brazilian legislation linked to the health sector, the Environmental Management System, established by ISO 14001, and application of two questionnaires: one for collecting data from the students and one for faculty and staff. The research was exploratory and descriptive approaches used to integrate qualitative and quantitative analysis. It was found that $94 \%$ of students are unaware of the legislation concerning RSS and that $82 \%$ of teachers and officials do not know the destination of the waste. Other survey results demonstrated the need for more extensive and consistent information regarding RSS, generated in practical classes and community service. The knowledge of both the students and the faculty and staff, is focused and specific to each situation, there is a gap in the legislation and management of RSS. After the results were compiled systematic suggestions about Waste Management of Health Services, generated in teaching, which is a set of actions aiming at the quality and efficiency of academic practices, emphasizing environmental education.
\end{abstract}

Keywords: Environmental Education, Environmental Policy Internal, Waste Management of Health Service. 


\section{INTRODUÇÃO}

A gestão dos resíduos é um dos grandes desafios que a sociedade enfrenta no início do terceiro milênio. Esta gestão procura minimizar a poluição causada ao meio ambiente buscando formas de reaproveitar os resíduos gerados. (ANDRADE e SILVA, 2011). Desde a sua origem as sociedades humanas tiveram necessidade de solucionar essas questões, porém, o aumento da população, bem como sua concentração em centros urbanos, o desenvolvimento tecnológico e a evolução cultural têm tornado essa realidade mais complexa.

Para Schneider et al. (2004), a nossa civilização está sujeita a expansão de formas de vida social que preservem a sua dignidade e a harmonia com o meio ambiente, indispensáveis para a sobrevivência da espécie. A complexidade dos aspectos envolvidos na problemática ambiental moderna exige um rigoroso e profundo exame das imposições éticas, culturais, científicas, políticas, econômicas e sociais subjacentes a ela.

O despertar da questão ecológica surge entre os elementos que identificam e diferenciam a particularidade do atual momento na história, transpondo as diversas dimensões da atividade humana. A consciência sobre problemas e questões socioambientais deve perpassar todas as ações do homem. Segundo Goleman (2009), a inteligência ecológica faz parte da natureza das pessoas, todos a possuímos, alguns mais, outros menos.

Leff (2003) salienta que a complexidade ambiental não se revela no mundo objetivo nem provém da evolução da matéria; ela surge como um novo entendimento sobre a produção do universo baseado no conhecimento, na tecnologia e na ciência. É o espaço onde a cultura, a técnica e a natureza se articulam. A complexidade ambiental emerge da abertura para um novo diálogo de saberes e de novas subjetividades. O saber ambiental origina de uma nova epistemologia e de uma nova ética em que os conhecimentos se fundem, se internalizam saberes e se projetam valores.

O gerenciamento dos resíduos gerados pela sociedade moderna é uma necessidade que se apresenta incontestável e requer não apenas a organização e a sistematização das fontes geradoras, mas fundamentalmente o despertar de uma consciência coletiva quanto às responsabilidades individuais no trato com esta questão.

A Pesquisa Nacional de Saneamento Básico, realizada pelo Instituto Brasileiro de Geografia e Estatística, em 2000 (IBGE, 2002), revela que $33 \%$ dos municípios e quatro das cinco grandes regiões são afetados pela contaminação dos solos. As maiores proporções de ocorrências foram no Sul (50\%) e no Sudeste (34\%).

Das 22 cidades brasileiras, com mais de 500 mil habitantes, em 13 os resíduos das atividades de saúde afetam, como seu principal agente, um número maior de municípios que os resíduos industriais.

O estudo também revelou um cenário dramático referente aos Resíduos de Serviços de Saúde - RSS. Somente 63\% dos municípios possuem coleta de RSS e, desses, apenas 18\% utilizam algum tipo de tecnologia para o tratamento dos mesmos, enquanto $36 \%$ queimam esses resíduos a céu aberto e cerca de $35 \%$ não adotam qualquer tipo de tratamento (IBGE, 2002).

Segundo o Ministério da Saúde (BRASIL, 2010), o brasileiro gera em média 149 mil toneladas de resíduos urbanos por dia. Avalia-se que a geração de RSS esteja entre 1,49 e 4,47 toneladas, o que representa de $1 \%$ a $3 \%$ desse volume diário.

Os resíduos procedentes da assistência à saúde, quando gerenciados de forma inadequada, são contaminantes potenciais do solo, da água e do ar e, portanto, estão inseridos no grupo que exige tratamento específico para a preservação do meio ambiente. Uma grande quantidade dos resíduos gerados e manipulados nas instituições de ensino de saúde é considerada de elevado risco, uma vez que podem afetar a saúde das pessoas e causar danos ao meio ambiente.

Os Resíduos Sólidos de Serviços de Saúde - RSSS dentro desta dimensão maior constituem um desafio com interfaces, uma vez que, além das questões ambientais inerentes a qualquer tipo de resíduo, os RSS incorporam uma preocupação maior no que tange o controle de infecções nos ambientes prestadores de serviços nos aspectos da saúde individual/ocupacional e a saúde pública. Há, portanto, necessidade de se fazer um diagnóstico exato das características locais e da produção dos RSSS, no sentido de se proporem soluções técnicas adequadas e viáveis para a realidade local (LIPPEL, 2003; BAIERLE, 2012).

Para Bolzan e Gracioli (2012), a importância da preservação do meio ambiente deve ser ressaltada no meio acadêmico, pois a partir dele é possível se obter uma consciência ambiental e social. Sendo que Rivetti et al. (2012), salienta que o gerenciamento dos resíduos gerados também deve ocorrer dentro dos centros universitários, principalmente onde ocorram intensas atividades de pesquisa. E estas instituições tem um compromisso com o meio ambiente, formando profissionais responsáveis e aptos a desempenharem seu 
trabalho com consciência ambiental. (KROHLING et al., 2013).

Como objetivos dessa pesquisa, propôs-se elaborar um Sistema de Gestão de Resíduos de Serviços de Saúde nos cursos de graduação da área da saúde numa universidade comunitária, a partir da análise do gerenciamento dos RSS, promovendo a educação ambiental, bem como a avaliação do inventário destes resíduos.

\section{METODOLOGIA}

Trata-se de uma pesquisa exploratória descritiva com abordagens de integração entre análise qualitativa e quantitativa realizada em uma Universidade Comunitária da região sul do país, enfocando quatro cursos de graduação da área da saúde que geram RSS: Enfermagem, Farmácia, Medicina e Odontologia. As informações foram coletadas através de questionários com 237 alunos e 78 docentes e funcionários e de conversas informais, observações e análises documental. A amostra foi dimensionada considerando um erro de $5 \%$ e um intervalo de confiança de $95 \%$. Nos questionários foram abordadas, entre outras questões sobre RSS, conhecimentos, vivências e práticas adotadas neste processo. Para análise dos dados foi utilizado o programa estatístico SPSS - PASW Statistics 18.

\section{RESULTADOS E DISCUSSÕES}

Acompanhou-se o roteiro realizado pela empresa terceirizada no recolhimento dos RSS, onde foi possível observar as salas de armazenamento temporário, todas atendendo às normas da legislação. O sistema de Gestão de RSS consiste em recolhimento dos resíduos colocados nas lixeiras e na transferência destes para uma sala de armazenamento temporário.

Esse recolhimento, segundo o programa de coleta e destinação final dos resíduos, é feito por uma empresa terceirizada (quando os resíduos são do grupo A, B e E) e encaminhados para incineração; os resíduos do grupo D são destinados para o programa de coleta seletiva da Universidade; e o rejeito ou "lixo comum" é recolhido pela prefeitura municipal e enviado para aterro sanitário.

A primeira etapa do inventário foi feita através do levantamento de RSS gerados em cada laboratório: Laboratórios de Anatomia, Laboratórios da Farmácia, Laboratórios da Odontologia e do Serviço Integrado de Saúde - SIS. Na avaliação do inventário, identificou-se que os RSS são separados por Grupo A e Grupo B; o volume gerado é relacionado em planilhas mensais, onde consta o número de recipientes (bombonas) por laboratório, o grupo, o valor do recipiente e o valor total. O número estimado de recipientes de 200 litros no período de agosto a dezembro de 2011 (período letivo) foi de 126 unidades, uma média de 25,2 unidades por mês, totalizando 5.040 litros mensais e 25.200 litros no semestre. Nesse mesmo período, o SIS gerou um volume de 18 recipientes de 50 litros (900 litros).

A etapa seguinte do inventário consistiu na colocação dos resíduos da mesma classe e grupo nos recipientes e a sua quantificação. Para a avaliação do conhecimento sobre o gerenciamento dos

Quadro 1: Resultado da pesquisa com os alunos

\begin{tabular}{|l|c|c|c|}
\hline Questão & Sim (\%) & Não (\%) & $\begin{array}{c}\text { Não Sabe } \\
\text { (\%) }\end{array}$ \\
\hline $\begin{array}{l}\text { 1. Recebeste orientação sobre os Resíduos de Serviços de } \\
\text { Saúde (RSS)? }\end{array}$ & 62,9 & 33,7 & 3,4 \\
\hline 2. A orientação sobre RSS é adequada à prática profissional? & 54,4 & 11,9 & 33,7 \\
\hline 3. Você conhece a classificação dos RSS? & 35,4 & 57 & 7,6 \\
\hline $\begin{array}{l}\text { 4. Você utiliza Equipamentos de Proteção Individual adequados } \\
\text { para o manuseio dos RSS? }\end{array}$ & 67,9 & 18,2 & 13,9 \\
\hline 5. Você recebeu instruções para a separação dos RSS? & 57,8 & 34,6 & 7,6 \\
\hline 6. Conhece o potencial de risco dos RSS? & 70,5 & 22,3 & 7,2 \\
\hline 7. Você conhece a destinação dos RSS gerados? & 38,0 & 54,4 & 7,6 \\
\hline 8. Você possui imunização através de vacinas? & 85,6 & 11,4 & 3,0 \\
\hline 9. Você conhece alguma legislação referente aos RSS? & 5,9 & 82,3 & 11,8 \\
\hline
\end{tabular}

Fonte: autores 
RSS foram aplicados dois questionários distintos: um para os alunos e um para os docentes, funcionários e bolsistas. As questões que compunham os questionários estão expressas nos quadros $1 \mathrm{e}$ 2 respectivamente.

Apesar de mais de $60 \%$ dos participantes responderem que receberam orientação sobre RSS, a qual estava contemplada na questão $\mathrm{n}^{\circ} 1$, mais de $30 \%$ não souberam responder a questão complementar: "se sim, qual a disciplina?" Foram citadas mais de trinta disciplinas diferentes.

Nas observações e nas conversas informais com alunos e funcionários, verificou-se que a prática adotada sobre a segregação e classificação dos RSS é para os perfurocortantes (dispostos em caixas apropriadas) e os demais resíduos são considerados contaminados, quando manipulados dentro das clínicas de odontologia, por exemplo. Em outros laboratórios a separação é feita de acordo com o tipo de resíduo, sendo que as caixas, os plásticos (embalagens de medicamentos, soro, etc.) e o papel toalha são separados para a coleta seletiva. Os resíduos de curativos (gaze, algodão, luvas, ataduras e espátulas) são considerados "lixo séptico" (contaminado).

Os resultados da pesquisa em relação ao grau de orientação sobre os Resíduos de Serviços de Saúde, sua adequação à prática profissional e o conhecimento do potencial de risco desses resíduos, mostram-se contraditórios com o índice superior a $80 \%$ dos respondentes que não conhecem nenhuma legislação referente a estes resíduos.

Percebe-se que a carência por projetos comprometidos com a temática de resíduos, tal como evidenciado por Rivetti et al. (2012), é uma situação comum e que ocorre também nas atividades de ensino, pesquisa e extensão nas universidades.

É significativo que mais de $60 \%$ dos respondentes não conheçam a classificação dos RSS, considerando-se que, dos $35,4 \%$ de respostas "Sim" não consideraram a classificação baseada na RDC $306 / 2004$, uma vez que não possuem o conhecimento da legislação.

Percebe-se que o aluno, de maneira geral, ainda não descobriu a sua "inteligência ecológica" (GOLEMANN, 2009). Talvez falte alguma disciplina no currículo acadêmico que possibilite esse despertar que se faz tão urgente na sociedade mundial contemporânea.

É relevante o dado que $94,1 \%$ dos alunos pesquisados não têm conhecimento sobre as legislações vigentes que tratam sobre os RSS, seja no país, no estado ou no município. A legislação constitui base de conhecimento e, de acordo com outras perguntas que visam identificar esse conhecimento, o resultado mais uma vez confirma essa carência. Verifica-se que o assunto está difuso nas diversas disciplinas, pois não existe uma com foco específico que trate o tema de maneira que favoreça o aprendizado e a sensibilização necessária, ampliando o entendimento para além da noção. Algumas observações sobre a questão foram:

- "Poderia ser um assunto com maior abordagem no curso, em mais momentos da faculdade".

- "Não há uma disciplina específica".

- "A orientação sobre resíduos na disciplina foi bem sucinta, não foi muito abordado".

Percebe-se que existe uma grande lacuna no processo ensino-aprendizagem referente aos RSS gerados nas aulas práticas e nos atendimentos à comunidade nos cursos, acima referidos, por aquela universidade em específico. Além disso, alguns depoimentos mostram total desconhecimento sobre o tema, o que insere a necessidade de introdução em disciplinas ou em treinamentos suplementares, a fim de suprir essa falta.

"... as orientações que recebemos são de como fazer e o que fazer com os resíduos para atender as práticas especificas de cada disciplina".

Esse depoimento reforça a percepção da necessidade de um trabalho mais focado no gerenciamento dos RSS e nas questões ambientais, buscando disseminar o conhecimento que possibilite criar uma visão mais ampla de tudo o que envolve essa temática, a fim de oportunizar ao aluno maiores condições de estabelecer a visão sistêmica do processo.

Neste contexto, deve-se ressaltar que a prática da educação ambiental é fundamental para sensibilizar e despertar a conscientização nas pessoas sobre o seu papel transformador e, conforme Pelicioni (2005), essa educação deve ser permanente e contínua focada na participação e no humanismo; que possibilite o desenvolvimento das habilidades essenciais para a resolução de problemas ambientais.

Percebe-se que há necessidade de habilitar as pessoas para a pró-atividade, a ética, a atuação competente tornando-as mais críticas e conscientes de seus papeis na transformação social.

Em 2004, foi realizado um estudo-piloto sobre os RSS gerados no SIS, com objetivo de conscientizar sobre a separação correta e minimizar a geração de resíduos pelos frequentadores, que são professores, alunos, funcionários e usuários. Segundo Kipper et al. (2005), a minimização da incidência de doenças e impactos ambientais é decorrente de um programa correto de geren- 
ciamento interno e da destinação adequada de resíduos gerados em serviços de saúde.

Alguns resultados da pesquisa com os docentes, funcionários e bolsistas estão dispostos à seguir no quadro 2 .

$\mathrm{Na}$ questão sobre o correto armazenamento dos resíduos, não obstante o alto índice de respostas afirmativas, percebeu-se nas conversas informais que um número significativo de pessoas não possui informações sobre o gerenciamento desses resíduos.

São realizadas capacitações eventuais para a equipe de higienização da Universidade; porém, observou-se que a frequência da sua realização é insuficiente e que deveriam acontecer em todos os laboratórios e para todos os agentes envolvidos.

O somatório das respostas "Não" e "Não Sabe" corresponde, exatamente, a 2/3 dos docentes, funcionários e bolsistas - participantes da pesquisa - desconhecem a legislação referente aos RSS.

É significativo o percentual de $82,1 \%$ dos docentes e funcionários, dos cursos pesquisados, que não possuem conhecimento sobre a destinação dos RSS por eles gerados. Os RSS são encaminhados para incineração, através de uma empresa contratada, e as cinzas são levadas para um aterro sanitário.

A incineração é a tecnologia mais utilizada para destinação de RSS no Brasil e, a exemplo da China, segundo Chen et al. (2009), mesmo que a técnica ofereça algumas vantagens como, por exemplo, redução de volume e peso, alto grau de desinfecção e a possibilidade de utilização do calor como fonte de energia; em virtude do aumento da conscientização ambiental a busca por tecnologias de autoclave, tratamento químico e microondas devem ser adotadas com maior frequência

Com base nos resultados da pesquisa pode-se considerar que esses cursos apresentam necessidades de espaços de reflexão e discussão - que oportunizem um maior aprendizado sobre o tema - a serem elaborados, desenvolvidos e implantados na Universidade. Para a capacitação da comunidade acadêmica responsável pela geração dos RSS, foi desenvolvido material para ser usado nas oficinas e workshops.

Para propor um sistema de gestão de RSS, elaborou-se o diagrama de causa-efeito a partir do resultado da pesquisa, do referencial teórico, das observações e dos depoimentos. Além disso, o modelo foi baseado no Sistema de Gestão Ambiental ISO 14001 e 14004/2004, nas orientações fornecidas na $\mathrm{RDC} \mathrm{n}^{\circ}$ 306/2004 da ANVISA e no Manual de Gerenciamento de Resíduos de Serviços de Saúde da ANVISA (2006). A figura 1, a seguir, demonstra o fluxograma do modelo proposto para gestão de Resíduos de Serviços de Saúde.

A primeira etapa a ser seguida é definir a equipe de trabalho responsável pelo Sistema de Gestão de RSS a ser implantado nos cursos e estabelecer pontualmente a função e as atribuições de cada integrante conforme a sua qualificação, competência e formação técnica. Assim, os demais funcionários saberão a quem se dirigir quando quiserem expor suas opiniões e ideias ou para sanar dúvidas. Importante destacar que para a elaboração e implantação de qualquer programa ou sistema de gestão há necessidade de construção coletiva e instrução prévia sobre o assunto aos profissionais envolvidos.

Quadro 2: Resultado da pesquisa com os docentes, funcionários e bolsistas.

\begin{tabular}{|l|c|c|c|}
\hline Questão & Sim (\%) & Não (\%) & $\begin{array}{c}\text { Não Sabe } \\
\text { (\%) }\end{array}$ \\
\hline 1. Os resíduos são armazenados corretamente? & 80,8 & 3,8 & 15,4 \\
\hline 2. Os resíduos são manuseados por pessoas capacitadas? & 70,5 & 7,7 & 21,8 \\
\hline $\begin{array}{l}\text { 3. Conhece o potencial de risco dos Resíduos de Serviços } \\
\text { de Saúde (RSS)? }\end{array}$ & 91,0 & 5,2 & 3,8 \\
\hline $\begin{array}{l}\text { 4. Os custos de transporte e disposição final dos RSS são } \\
\text { quantificados? }\end{array}$ & 25,6 & 2,6 & 71,8 \\
\hline $\begin{array}{l}\text { 5. Conhece alguma legislação referente aos resíduos } \\
\text { gerados no laboratório? }\end{array}$ & 33,3 & 25,7 & 41 \\
\hline 6. Você conhece a destinação final dos RSS? & 17,9 & 33,3 & 48,8 \\
\hline $\begin{array}{l}\text { 7. O seu curso possui um Plano de Gerenciamento de } \\
\text { Resíduos de Serviços de Saúde (PGRSS)? }\end{array}$ & 16,6 & 10,3 & 73,1 \\
\hline
\end{tabular}




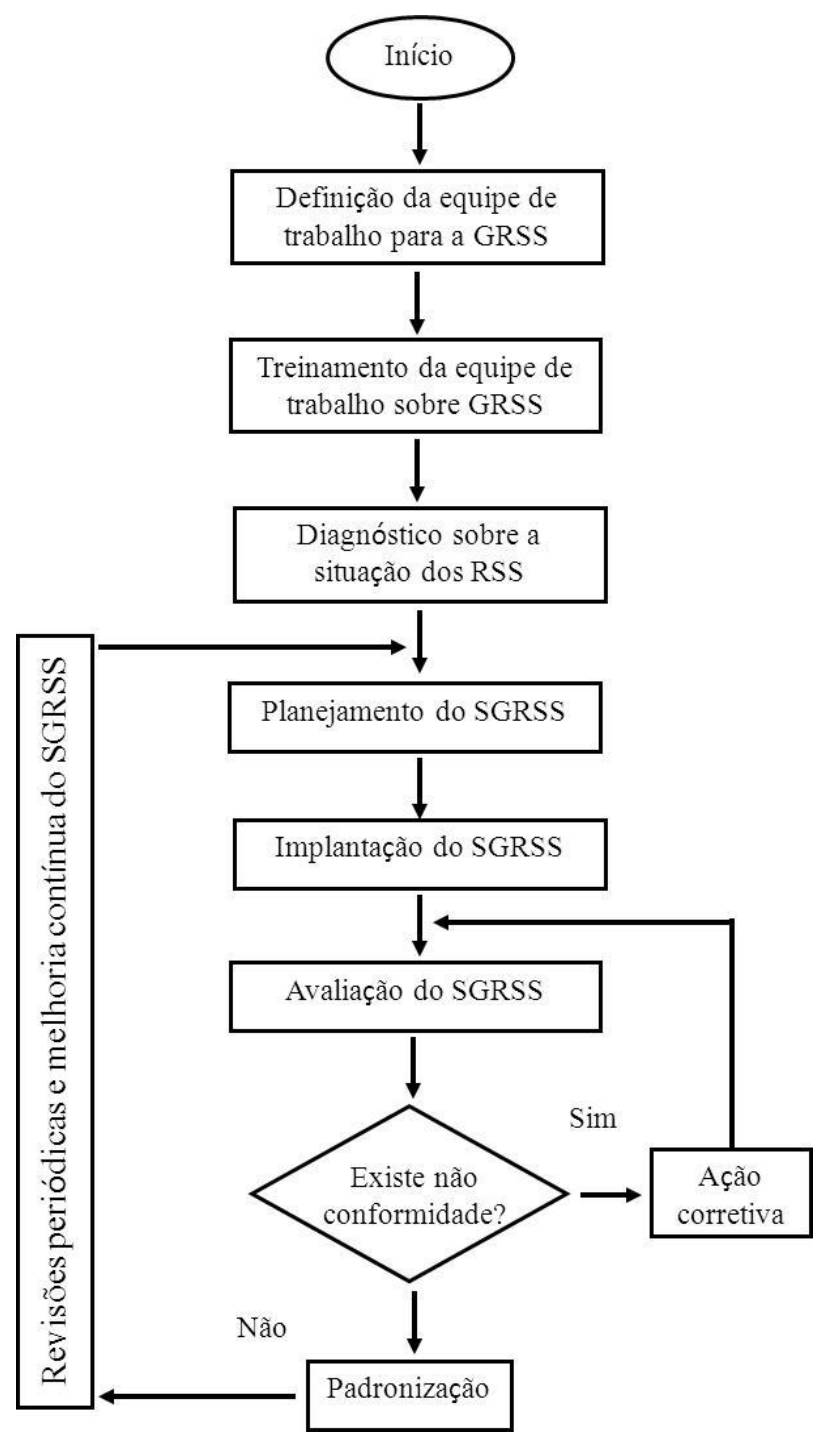

Figura 1: Fluxograma do modelo proposto para gestão de Resíduos de Serviços de Saúde

Identificou-se que há uma grande necessidade de informações sobre o gerenciamento de resíduos de serviços de saúde (todas as suas etapas) e, também, em relação à legislação.

Assim, após a definição da equipe responsável pela Gestão de RSS, a capacitação é fundamental para o início da elaboração e implantação do SGRSS, bem como, a previsão da sua continuidade deve ser definida no PGRSS.

$O$ treinamento da equipe pode ser realizado através da oferta de oficinas de capacitação (workshops), palestras e cursos adotando como base o conteúdo de algumas referências: RDC $\mathrm{n}^{\circ}$ 306/2004 ANVISA - dispõe sobre o regulamento técnico para o gerenciamento dos RSS, Resolução CONAMA n 358/2005 - dispõe sobre o tratamento e a disposição final dos resíduos de serviços de saúde e dá outras providências; NBR n ${ }^{\circ}$
10.004/2004, além do Manual de Gerenciamento de Resíduos de Serviços de Saúde (ANVISA, 2006).

Os gestores responsáveis pelo SGRSS devem ser multiplicadores desses conhecimentos aos demais agentes envolvidos no processo de gerenciamento de RSS, além de buscar a mobilização de toda a Instituição para as orientações adequadas.

Para a definição e elaboração do Planejamento do Sistema de Gestão de RSS, o diagnóstico possui importância essencial. Assim, devem-se registrar as informações com o maior cuidado possível, a fim de que representem a situação como ela realmente acontece para que reflita as necessidades reais da Instituição, de modo a evitar desperdícios de recursos humanos, materiais e financeiros.

Conforme ANVISA (2006), a gestão de 
resíduos deve priorizar a não geração, a minimização da geração e o reaproveitamento dos resíduos, com a finalidade de evitar os efeitos negativos à saúde pública e ao meio ambiente.

O Planejamento do Sistema de Gestão de Resíduos de Serviços de Saúde deve seguir algumas orientações como, por exemplo:

a) reunir procedimentos consistentes e fundamentados em normas e legislações específicas para que se estabeleçam metas e programas compatíveis com a realidade local;

b) objetivar a minimização da geração de resíduos, bem como proporcionar um manejo seguro e eficiente desses resíduos, visando à proteção dos trabalhadores, à preservação da saúde e do meio ambiente; e,

c) realizar o maior aproveitamento possível, através da segregação dos materiais recicláveis, reduzindo os custos de coleta, tratamento, transporte e disposição final. Esses procedimentos deverão formar o PGRSS da Instituição, que deverá ser elaborado nessa etapa.

Após a definição das ações e procedimentos, deverão ser descritos os objetivos e as metas e definido um cronograma. É importante a elaboração de um quadro de intenções com as determinações necessárias para a realização dos trabalhos. Isso possibilitará o dimensionamento da equipe de trabalho, a priorização das metas e objetivos, a viabilização dos materiais, equipamentos e espaço físico, bem como a percepção do momento mais apropriado para o início da implantação do SGRSS.

Para o estabelecimento do plano de ação, que é um conjunto de contramedidas com a finalidade de bloquear as não conformidades, pode-se utilizar as ferramentas gerenciais $5 \mathrm{~W} 2 \mathrm{H}$ e Ciclo PDCA de melhorias, que definem, sistematizam e monitoram com eficiência a gestão dos processos, com base no diagnóstico das situações indesejáveis e na busca de soluções, que devem ser precedidas de definições e planejamentos adequados ao processo.

De acordo com as características diagnosticadas, os tipos de resíduos identificados e suas classificações, o SGRSS para os cursos de Enfermagem, Farmácia, Medicina e Odontologia da Universidade, deve prever e estabelecer ações e procedimentos específicos para o gerenciamento correto dos resíduos gerados, que deverão constar no PGRSS.

Depois de finalizado o Planejamento do Sistema de Gestão de Resíduos de Serviços de Saúde; definidos os objetivos; as metas e o tempo para a implantação; obtida a aprovação dos gestores da instituição e os recursos necessários, inicia-se a etapa da implantação.
Na etapa de Implantação são efetuadas as ações e os procedimentos determinados no Planejamento do SGRSS. Nessa fase há necessidade de se elaborar um plano de contingência até a conclusão da implantação.

A participação na elaboração, a definição das responsabilidades e as atribuições das pessoas que farão parte da equipe de trabalho devem ser definidas nessa etapa, de modo que todos se sintam envolvidos e comprometidos com o sistema a ser implantado. A alta direção da instituição deve ratificar seu comprometimento, atuando juntamente com a equipe na implantação demonstrando, assim, a relevância e seriedade do trabalho que está sendo executado.

Para atender ao sistema de gestão de resíduos deve-se integrar essa temática nas aulas, através da educação inicial e continuada visando à redução da geração de resíduos, à separação correta e à destinação adequada. Pode-se dispor material específico sobre os RSS na website da Universidade.

Identificou-se que os cursos (Enfermagem, Farmácia, Medicina e Odontologia) apresentam necessidades de espaços para reflexão e discussão - que oportunizem um maior aprendizado sobre o tema - a serem elaborados, desenvolvidos e implantados na Universidade.

A gestão compreende as ações relativas às tomadas de decisões nos aspectos operacional, administrativo, financeiro, social e ambiental e o planejamento integrado é um instrumento importante no gerenciamento de resíduos em todas as suas etapas: geração, segregação, acondicionamento, transporte, até a disposição final, possibilitando que se determine de forma integrada e sistemática, em cada uma delas, programas, metas, sistemas organizacionais e tecnologias, adequados à realidade local.

A carência de informações sobre minimização da geração e separação adequada de resíduos, além da ausência de um plano de gerenciamento coerente com as necessidades e características dos cursos estudados, resulta num maior volume encaminhado para incineração e/ou destinação final, o que representa custos mais elevados e a probabilidade de causar riscos ocupacionais e danos ao meio ambiente.

O levantamento das informações para o estudo sobre a questão dos RSS, nos cursos que geram esses resíduos, procura identificar as áreas críticas e as medidas possíveis de serem instituídas. Para auxiliar nessa etapa, pode-se usar algumas ferramentas da qualidade, como por exemplo, o diagrama Espinha de Peixe ou Diagrama de Ishikawa 
que visa estabelecer a relação entre o efeito e todas as causas de um processo. Conforme Rodrigues (2004), além de contribuir para a solução do problema, essa ferramenta envolve os membros com as causas e os objetivos organizacionais e motiva o trabalho em equipe.

O Plano de Gerenciamento de Resíduos de Serviços de Saúde (PGRSS) deverá ser elaborado conforme as especificações da Resolução ${ }^{\circ}$ 358/2005 do CONAMA e da RDC n 306/2004 da ANVISA e deverá registrar todas as ações para o manejo adequado dos RSS gerados, de acordo com as características apresentadas, considerando todos os aspectos relacionados às suas etapas, desde a geração até à disposição final, bem como as ações de proteção à saúde e ao meio ambiente e a adoção dos princípios de biossegurança para a prevenção de acidentes.

Isso possibilitará o dimensionamento da equipe de trabalho, a priorização das metas e objetivos, a viabilização dos materiais, equipamentos e espaço físico, bem como a percepção do momento mais apropriado para o início da implantação do SGRSS.

$\mathrm{Na}$ etapa de avaliação Sistema de Gestão de Resíduos de Serviços de Saúde, os resultados alcançados com a Implantação do SGRSS são verificados e avaliados para que o sistema possa ser corrigido, padronizado e melhorado continuamente. Isso pode ocorrer através da verificação, do monitoramento e da análise crítica do sistema implantado, de acordo com os objetivos e metas estabelecidos.

A verificação do SGRSS constitui-se em averiguar e avaliar as conformidades e não conformidades existentes no processo; se os resultados esperados estão sendo alcançados ou se está na iminência de acontecer e, se houver diferenças, identificar os reais motivos; avaliar a escolha dos mecanismos e substituí-los se facilitarem o alcance dos objetivos e metas; elaborar um quadro de acompanhamento da avaliação efetuada e dos resultados identificados.

O monitoramento propõe-se a acompanhar o desempenho do sistema implantado para que assegure a melhoria contínua do processo e se possam identificar as oportunidades de melhorias com base nos resultados alcançados, visando ao alcance dos objetivos propostos.

A análise crítica é de importância relevante em nível operacional e estratégico, porque se constitui em: revisar o SGRSS implantado para assegurar a melhoria contínua; buscar adequação, desempenho e eficácia; debater com a equipe responsável pelo SGRSS e com a alta direção os ajustes que julgarem necessários.

Os principais aspectos que a pesquisa identificou foram em relação ao desconhecimento das questões referentes aos RSS por parte dos alunos e, também, dos docentes e funcionários. O conhecimento aplicado às práticas ainda é insuficiente, limitado e fragmentado. A realização de mudanças de procedimentos, também contribui para minimizar a geração dos resíduos.

Pode-se dizer que o modelo proposto constitui-se num conjunto de ações para o gerenciamento de Resíduos de Serviços de Saúde gerados nas práticas de ensino e nos atendimentos prestados à comunidade, visando a uma maior conscientização e a um ganho ambiental e financeiro.

\section{CONCLUSÕES}

A pesquisa propiciou o conhecimento e a análise das atuais práticas de gestão dos Resíduos Sólidos de Serviço de Saúde nesta Universidade, observando-se que é possível a adoção de algumas medidas, tais como melhorar o sistema de separação por classe e por grupo de resíduos e adotar práticas de minimização da geração desses resíduos.

Durante a pesquisa foi possível executar ações de educação ambiental, de forma a sensibilizar os sujeitos da pesquisa e os demais envolvidos, através da realização de palestras e o desenvolvimento de um produto capaz de ser o agente inicial para a divulgação de ações de educação ambiental, como um marcador de páginas, de fácil divulgação e aceitação. Foi possível realizar levantamento parcial dos Resíduos de Serviço de Saúde gerados nas práticas dos cursos estudados na Instituição, podendo o mesmo servir como base para novas propostas de destinação dos mesmos resíduos.

A proposta de um Sistema de Gestão de Resíduos de Serviços de Saúde - SGRSS como instrumento de gestão é de grande importância para uma atuação mais qualificada, econômica e responsável, tanto para os cursos envolvidos como para a Instituição como um todo, principalmente pelo aprendizado a todos envolvidos no processo. Tal proposta culminou a pesquisa desenvolvida com o envolvimento de todos os segmentos interessados.

\section{AGRADECIMENTOS}

Os autores agradecem a UNISC pelo auxílio financeiro por meio de bolsas de estudo na modalidade de Iniciação Científica e do FAP Fundo de Apoio à Pesquisa. 


\section{REFERÊNCIAS}

ANDRADE, T. R.; SILVA, C. E.. Análise de sustentabilidade na gestão de resíduos sólidos na cidade: o caso de Paripiranga, Bahia, Brasil. Revista Ibero-Americana de Ciências Ambientais, Aquidabã, v.2, n.1, p.59-84, 2011.

ASSOCIAÇÃO BRASILEIRA DE NORMAS TÉCNICAS - ABNT NBR ISO 14001:

sistemas de gestão ambiental: requisitos com orientações para uso. Rio de Janeiro, 2004.

ASSOCIAÇÃO BRASILEIRA DE NORMAS TÉCNICAS - ABNT NBR 10004 - Resíduos Sólidos: classificação. Rio de Janeiro, 2004.

BAIERLE, J.L. Plano de Gerenciamento de Resíduos de Serviço de Saúde na Clínica de Odontologia da UNISC. Monografia (Graduação em Engenharia Ambiental) - Universidade de Santa Cruz do Sul. Santa Cruz do Sul, 2012.

Bolzan, A. Z. e Gracioli, C. R. (2012), "Ações de Educação Ambiental na Escola Municipal de Ensino Fundamental João Pessoa - São Sepé, RS", Revista Eletrônica em Gestão, Educação e Tecnologia Ambiental. Vol. 6, No. 6, pp. 1007 - 1014.

BRASIL. Ministério da Saúde. Manual de gerenciamento de resíduos de serviços de saúde. Agência Nacional de Vigilância Sanitária, Brasília: Ministério da Saúde, 2006.

Resolução da Diretoria Colegiada - RDC n. 306/2004 da Agência Nacional de Vigilância Sanitária. Dispõe sobre o Regulamento Técnico para o Gerenciamento de Resíduos de Serviços de Saúde, 2006.

CHEN, Y.; Li, P.J.; LUPI, C.; SUN, Y.Z.; DIANDOU, X.; QIAN F.; SHASHA, F. Sustainable management measures for healthcare waste in China, Waste Management , 29, 2009.

GOLEMAN, D. Inteligência ecológica: o impacto do que consumimos e as mudanças que podem melhorar o planeta. Tradução: Ana Beatriz Rodrigues. Rio de Janeiro: Elsevier, 2009.

IBGE. Pesquisa nacional de saneamento básico 2000 . Rio de Janeiro: IBGE, 2002.
KIPPER, L. M.; MAHLMANN, C. M.; ALVES, G. RODRIGUEZ, A. L. WEISS, F. Gerenciamento de resíduos perigosos na universidade de Santa Cruz do Sul - RS. In: $23^{\circ}$ CONGRESSO BRASILEIRO DE ENGENHARIA SANITÁRIA E AMBIENTAL, Anais. Campo Grande - MS, 2005.

LEFF, E. A complexidade ambiental. Tradução: Eliete Wolff. São Paulo: Cortez, 2003.

LIPPEL, M. Modelo de gerenciamento de resíduos sólidos de saúde para pequenos geradores - o caso de Blumenau/SC. Dissertação (Mestrado em Engenharia de Produção) - Universidade Federal de Santa Catarina, Florianópolis, 2003.

MANEIA, A.; CUZZUOL, V. and KROHLING, A. (2013), "A Educação Ambiental e a Responsabilidade Socioambiental nas Práticas Ambientais em Instituições de Ensino Superior no Brasil", Revista Eletrônica em Gestão, Educação e Tecnologia Ambiental, Vol. 13, No. 13.

PELICIONI, M. C. F. Educação ambiental: evolução e conceitos. In: PHILIPPI JR, Arlindo (Editor). Saneamento, saúde e ambiente: fundamentos para um desenvolvimento sustentável. Baueri, SP: Manole, 2005.

RIVETTI, L. V.; SIMONATO, D. C.; COSTA, S. O.; FIGUEIREDO, R. A.. Análise documental e de percepção acerca da gestão de resíduos em um campus universitário (SP, Brasil). Revista Ibero-Americana de Ciências Ambientais, Aquidabã, v.3, n.1, p.98 $\square 111,2012$.

RODRIGUES, M. V. C. Ações para a qualidade: GEIQ, gestão integrada para a qualidade: padrão seis sigma, classe mundial. Rio de Janeiro: Qualitymark, 2004.

SCHNEIDER, V. E. et al. Manual de gerenciamento de resíduos sólidos de serviços de saúde. 2. ed. rev. e ampl., Caxias do Sul, RS: Educs, 2004. 